\title{
Alterações Morfológicas e na Contagem de Fibras Colágenas Induzidas pela Hialuronidase no Colo de Ratas Prenhes
}

\author{
Morphological and Collagen Fiber Count Alterations Induced \\ by Hyaluronidase in the Cervix of Pregnant Rats \\ Guilherme Negrão de Souza $^{1}$, Eduardo Cordioli' ${ }^{1}$, Manuel de Jesus Simões ${ }^{2}$ \\ Eduardo de Souza ${ }^{1}$, Luiz Kulay Júnior ${ }^{1}$, Luiz Camano ${ }^{1}$
}

\begin{abstract}
RESUMO
Objetivo: avaliar as alterações morfológicas e morfométricas na cérvice uterina da rata albina prenhe, determinadas pela administração local de hialuronidase.

Método: dez ratas com teste de prenhez positivo foram distribuidas aleatoriamente em dois grupos, numericamente iguais. O grupo controle foi constituido pelas ratas que receberam 1 $m L$ de água destilada, dose única, no $18^{\circ}$ dia da prenhez, sob anestesia, ministrado na cérvice uterina. O grupo experimental constou de ratas que receberam, sob as mesmas condições do grupo controle, 0,02 $\mathrm{mL}$ de hialuronidase, diluídos em 0,98 $\mathrm{mL}$ de água destilada (total de $1 \mathrm{~mL}$ ). No $20^{\circ}$ dia de prenhez, as ratas foram novamente anestesiadas e submetidas a dissecção, preparando-se a cérvice uterina para estudo morfológico e morfométrico à microscopia de luz (hematoxilina-eosina e tricrômio de Masson).

Resultados: verificou-se, no grupo experimental, maior adelgaçamento do epitélio superficial mucificado, com lâmina própria rica em vasos sangüineos e em eosinófilos, diferentemente do grupo controle, que mostrou grande concentração de fibras colágenas. A contagem histométrica do grupo experimental caracterizou-se por exibir menor número de fibras colágenas (média de 248 contra 552 do controle; erro padrão 49,7 contra 31,1 do controle). $O$ teste paramétrico (teste t de Student) mostrou diferença significativa entre os dois grupos $(p<0,0001)$.

Conclusão: o uso local de hialuronidase no colo de ratas prenhes determinou predominio de tecido conjuntivo frouxo e menor concentração de fibras colágenas.
\end{abstract}

PALAVRAS-CHAVE: Trabalho de parto. Maturação do colo. Hialuronidase. Colágeno.

\section{Introdução}

A obstetrícia atual ainda não desvendou, por completo, todas as lacunas envolvidas no determinismo do parto. Em outros mamíferos o conhecimento está melhor documentado, embora seja nitidamente diverso em humanos, princi-

${ }^{1}$ Departamento de Obstetrícia da Universidade Federal de São Paulo - Escola Paulista de Medicina - UNIFESP/EPM ${ }^{2}$ Departamento de Morfologia da Universidade Federal de São Paulo - Escola Paulista de Medicina - UNIFESP/EPM Correspondência:

Guilherme Negrão de Souza

Rua Loureiro da Cruz, 63, apto 61 B

01529-020 - São Paulo - SP

e-mail: guinsouza@bol.com.br

Fone (FAX): (11) 3271-8602 palmente no que se refere às alterações hormonais. O esvaecimento e a dilatação da cérvice uterina no final da gestação não resultam somente das contrações uterinas, mas também de outros processos complexos ${ }^{1}$.

Muito se discute, em nossos dias, sobre o verdadeiro papel do ácido hialurônico e das fibras colágenas no preparo da cérvice uterina para a parturição. Clinicamente, o uso intracervical de hialuronidase tem sido proposto como forma de acelerar o processo de esvaecimento e dilatação cervical, sendo indicada, também, nos casos de excesso de componente conjuntival cervical (colo esclerótico ou anelástico). Excluída a causa neoplásica, a ação da hialuronidase parece vantajosa, já que a cérvice uterina, em condições normais, tem cerca de $85 \%$ de tecido conjuntivo ${ }^{2}$. 
A hialuronidase poderia contribuir para a diminuição do índice de cesáreas, principalmente em nosso meio, onde a realização da tomotocia ultrapassa o parâmetro desejável máximo de 15\%, indicado pela Organização Mundial da Saúde ${ }^{3}$.

Pela dificuldade na escolha do método ideal para indução do parto, essa enzima vem sendo utilizada para facilitar a maturação cervical. Há, porém, carência de resultados histológicos comprobatórios de que a dose preconizada atualmente ocasione alterações estruturais significantes. A dose, o modo e o momento da aplicação foram idealizados empiricamente.

O uso de hialuronidase na maturação cervical tem ocorrido esporadicamente desde a década de 50, utilizando doses entre 200 a 1.000 unidades, com resultados variáveis na maturação cervical e na diminuição do tempo do trabalho de parto. As doses variavam de 1.000 a 20.000 unidades de hialuronidase intracervical com bons resultados na maturação cervical, diminuição do tempo de trabalho de parto e aumento da incidência de parto vaginal ${ }^{4}$.

Spallicci $^{4}$, em estudo clínico aleatorizado em gestações a termo, empregou a hialuronidase na dose de 20.000 unidades e concluiu que o tempo entre a primeira dose e o início do trabalho de parto para as gestantes que a receberam foi em média 44 horas (grupo controle de 60 horas) e de 54 horas quando empregou suplementação após 48 horas (grupo controle de 94 horas). O tempo de indução foi em média 14 horas menor comparado ao grupo placebo.

No mesmo estudo, para as pacientes que haviam recebido a hialuronidase, o tempo de trabalho de parto foi em média 7 horas para as nuliparas (placebo de13 horas) e de 5 horas para as primiparas/multíparas (placebo de 10 horas). A incidência de parto por via vaginal foi maior para as gestantes submetidas a hialuronidase (83\%) do que para o grupo placebo (51\%).

Surita $^{5}$, comparando o uso da hialuronidase com o da sonda de Foley no preparo cervical em gestações com indicação de indução de parto, concluiu que ambos os métodos aceleram a maturação cervical, sem mudanças significativas nos resultados perinatais, efeitos indesejáveis e complicações. No grupo da sonda de Foley, o trabalho de parto foi desencadeado mais rapidamente, com menor tempo de indução e dose de ocitócicos e maior ocorrência de partos vaginais. Kavanagh et al. $^{2}$, no entanto, concluíram que não existem ensaios clínicos conclusivos para o uso de hialuronidase como um método de preparo cervical durante a gestação.

A falta de registros histológicos que comprovem a ação da hialuronidase nos motivou a pesquisar, de forma experimental, a ação desta droga. O objetivo deste estudo foi avaliar, à microscopia de luz, as alterações morfológicas e a contagem de fibras colágenas na cérvice uterina da rata albina, determinadas pela ministração local de hialuronidase no final da prenhez.

\section{Material e Métodos}

Utilizamos ratas albinas (Rattus norvegicus albinus, Rodentia, Mammalia), com cerca de 90 dias de idade, virgens, pesando aproximadamente 200 gramas, da linhagem EPM - Wistar, oriundas do Centro de Desenvolvimento de Modelos Experimentais para Medicina e Biologia da Universidade Federal de São Paulo - Escola Paulista de Medicina.

Os animais foram transportados para o biotério, onde ficaram acondicionados em gaiolas coletivas de poliuretano (separados por sexo), medindo $45 \times 30 \times 15 \mathrm{~cm}$, respectivamente de comprimento, largura e altura com tampa gradeada de metal. Em cada gaiola ficaram 5 animais mantidos com alimentação e água "ad libitum", durante 7 dias, considerado como período de adaptação. A temperatura ambiente foi de aproximadamente $22^{\circ} \mathrm{C}$, com iluminação artificial, com lâmpadas fluorescentes, modelo luz do dia, sendo o fotoperíodo de 12 horas claro e 12 horas escuro, considerando o período de luz das 7:00 às 19:00 horas.

Após o período de adaptação, as ratas foram acasaladas na proporção de três fêmeas para cada macho, por periodo de 12 horas, durante o fotoperíodo escuro. O início da prenhez foi determinado pela presença de espermatozóides na vagina da rata. Este foi considerado o dia 0 (zero da prenhez).

Dez ratas com teste de prenhez positivo foram distribuidas aleatoriamente em dois grupos, numericamente iguais: Grupo I (G I) - ratas que receberam $1 \mathrm{~mL}$ de água destilada, dose única, no $18^{\circ}$ dia da prenhez, ministrado na cérvice uterina, que foi considerado grupo controle; Grupo II (G II) - ratas que receberam, também no $18^{\circ}$ dia da prenhez, por via intracervical, em dose única, sob as mesmas condições do grupo controle, 0,02 $\mathrm{mL}$ de hialuronidase, diluído em 0,98 $\mathrm{mL}$ de água destilada (total de $1 \mathrm{~mL}$ ). Foi considerado grupo experimental.

$\mathrm{Na}$ preparação da enzima ministrada ao $\mathrm{G}$ II, o frasco ampola de pó liofilizado foi diluído em 4 $\mathrm{mL}$ de água destilada, com movimentos giratórios sobre o próprio eixo para evitar a formação de espuma e facilitar a diluição do fármaco. A dose preconizada na rata foi proporcional à estabelecida para humanos, equivalente a 20.000 unidades ${ }^{4}$.

Para as injeções foram utilizadas seringas descartáveis de $1 \mathrm{~mL}$, esterilizadas por óxido de 
etileno. As ministrações foram praticadas sob anestesia (ketamina + xilazina $0,1 \mathrm{mg} / \mathrm{kg}$ ), com o auxílio de guia plástico em forma de cone, introduzido em toda a extensão da vagina da rata para orientação do trajeto da agulha (tipo "ponta de lápis", descartável e esterilizada por óxido de etileno). A agulha foi introduzida no guia e o limite de inserção foi definido pela sensação de barreira local. A seguir, realizamos leve pressão da agulha no local, percorrendo cerca de 2-3 milímetros (cérvice uterina) e injetamos a solução de 1 $\mathrm{mL}$; a ministração foi lenta (cerca de 5 segundos), com manutenção da agulha no local por cerca de 30 segundos, para evitar refluxo.

No $20^{\circ}$ dia da prenhez, as ratas foram novamente anestesiadas (ketamina + xilazina $0,1 \mathrm{mg} /$ $\mathrm{kg}$ ) às 9:00 horas. Imediatamente foram tricotomizadas na região abdominal e no intróito vaginal. Após a abertura do abdome, realizamos disjunção da sínfise púbica para facilitar a abertura longitudinal da vagina em toda a sua extensão, visualizando-se, destarte, a porção cervical.

Após cuidadosa observação dos órgãos pélvicos, em particular dos cornos uterinos, procedemos à dissecção e retirada da cérvice uterina. As peças foram imediatamente mergulhadas em solução de formaldeído a $10 \%$ para fixação, onde permaneceram por 24 horas; em seguida, foram desidratadas em concentrações crescentes de álcool etílico, diafanizadas pelo xilol, impregnadas e incluídas em parafina líquida na estufa, regulada à temperatura de $59^{\circ} \mathrm{C}$, a fim de obtermos, nas lâminas histológicas, cortes longitudinais da cérvice uterina.

Posteriormente, os cortes foram obtidos em micrótomo ajustado para $5 \mathrm{~mm}$. Foram então coletados em lâminas previamente untadas com albumina de Mayer e mantidos em estufa regulada à temperatura de $37^{\circ} \mathrm{C}$ por 24 horas, para secagem e colagem. As lâminas foram coradas pela técnica de hematoxilina-eosina para descrição morfológica e pelo tricrômio de Masson para ressaltar fibras colágenas e permitir a morfometria.

Para o estudo histológico utilizamos microscópio com ocular de aumento de 10 vezes e objetivas cujos aumentos variam entre 4 e 100 vezes. Para a contagem das fibras colágenas, nos dois grupos estudados, foi utilizado método morfométrico baseado nos princípios da estereologia, que, pela análise quantitativa, fornece valores percentuais dos componentes analisados no plano bidimensional, proporcionando uma noção do que ocorre no plano tridimensional; foi utilizada ocular integradora, contendo 25 pontos distribuídos geometricamente. O retículo da ocular integradora projetada sobre os cortes histológicos possibilitou a contagem de hits, ou seja, os pontos da ocular que incidiram nas fibras colágenas, ou em outras estruturas (resíduo). Para tanto, a ocular integradora foi acoplada em um microscópio de luz com objetiva de 100 , sendo o aumento final de 1.000 .

Com a finalidade de evitar vícios de contagem sobre os campos comuns em um mesmo corte, foi utilizado esquema pelo qual dividiram-se os cortes da cérvice uterina em quatro quadrantes, fazendose a leitura num determinado sentido. Em cada rata fez-se a contagem de 40 campos, perfazendo um total de 1.000 hits, totalizando 5.000 por grupo.

Para análise dos resultados numéricos (contagem de fibras colágenas) foi utilizado teste paramétrico, levando-se em conta a natureza das distribuições ou a variabilidade das mensurações efetuadas, aplicando-se o teste $t$ de Student. O nível de significância foi fixado em 0,05 ou $5 \%$. As médias e os erros-padrão da média foram calculados e apresentados a título de informação.

O experimento foi avaliado e aprovado pela Comissão de Ética em Pesquisa da Universidade Federal de São Paulo - Escola Paulista de Medicina.

\section{Resultados}

Nas figuras mostramos os achados microscópicos da cérvice uterina das ratas (microscopia óptica). No grupo controle notamos que o ectocérvice está revestido externamente por um epitélio pavimentoso estratificado. A lâmina própria é constituída por tecido conjuntivo denso, rico em fibras colágenas e fibroblastos. A endocérvice, por sua vez, é revestida por epitélio cilindrico simples e lâmina própria com estroma rico em fibras colágenas. Abaixo da lâmina própria, tanto no ectocérvice quanto na endocérvice, notamos fibras musculares lisas (Figura 1A e 1B).

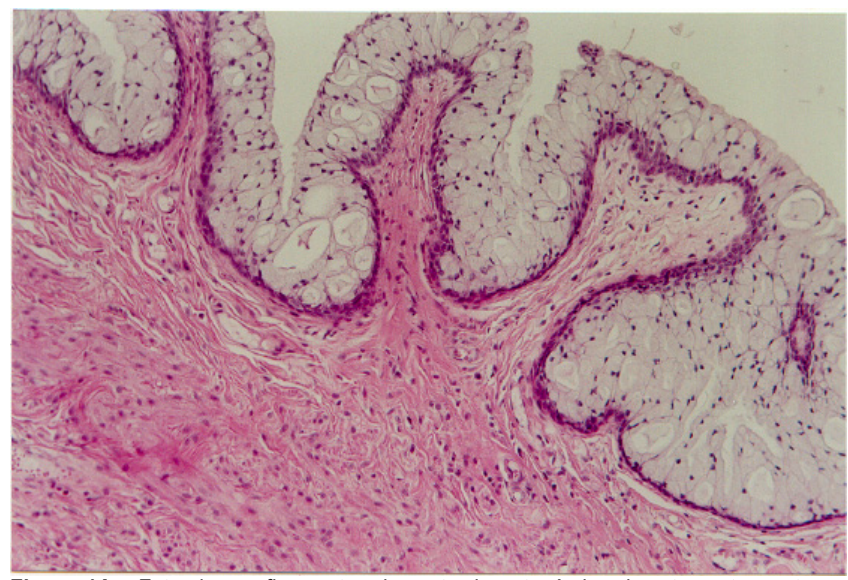

Figura 1A - Fotomicrografia mostrando parte da ectocérvice de rata pertencente ao grupo controle. Notar epitélio superficial mucificado $\left({ }^{*}\right)$ e lâmina própria (LP) constituída por tecido conjuntivo. Hematoxilina-eosina, 200X. 


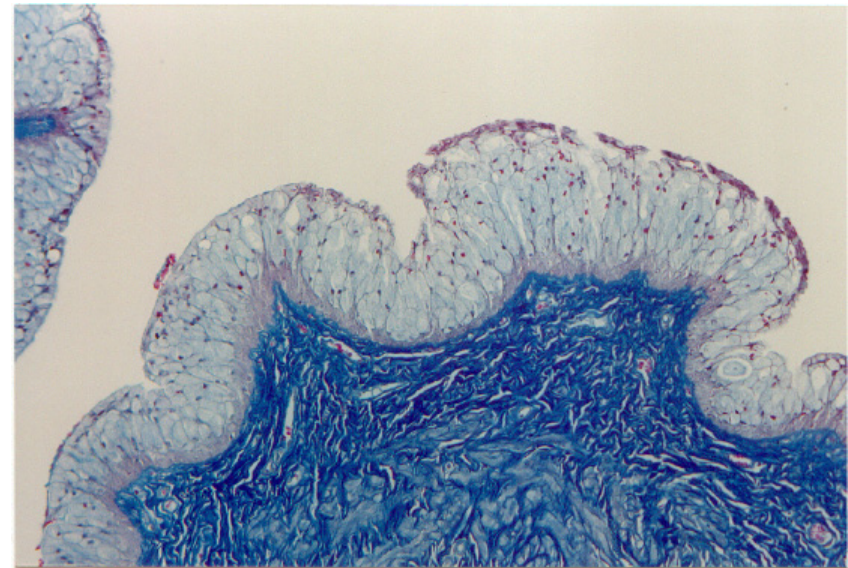

Figura 1B - Fotomicrografia mostrando parte da ectocérvice de rata pertencente ao grupo controle. Notar lâmina própria (LP) contendo grande concentração de fibras colágenas. Tricrômio de Masson, 200X.

No grupo experimental, as regiões da cérvice uterina da rata são semelhantes às do grupo controle, ou seja, estão constituídas pela ectocérvice e pela endocérvice. No entanto, na região da ectocérvice, local onde foi aplicada a medicação, notamos epitélio superficial delgado e lâmina própria constituída por tecido conjuntivo frouxo. Nesse local identificamos ainda a presença de eosinófilos e vasos sangüíneos bem dilatados (Figura 2A e 2B).

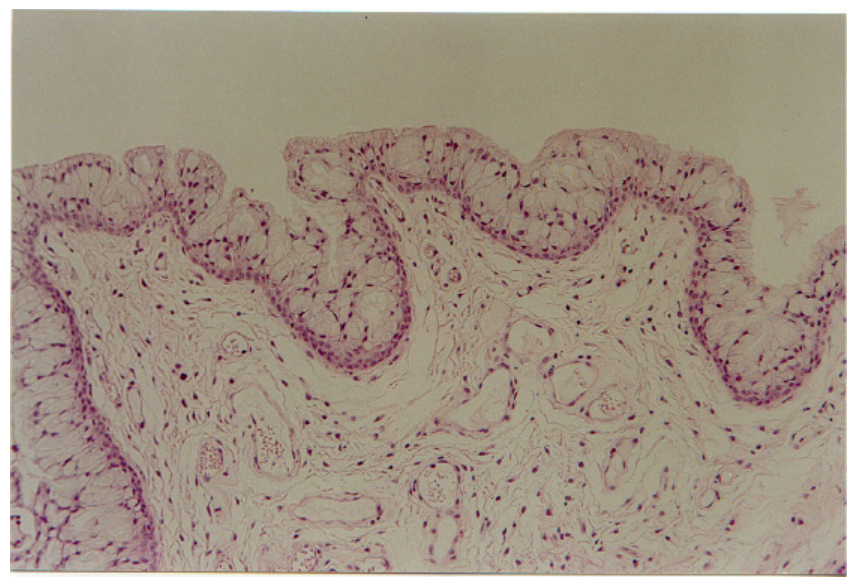

Figura 2A - Fotomicrografia mostrando parte da ectocérvice de rata pertencente ao grupo tratado com hialuronidase. Notar epitélio superficial mucificado delgado (*), lâmina própria rica em vasos sangüíneos e em eosinófilos (setas). Hematoxilina-eosina, 200X.

Quanto à contagem histométrica das fibras colágenas, observamos que o grupo que recebeu a hialuronidase intracervical (G II) apresentou número estatisticamente menor de fibras colágenas, quando comparado ao grupo controle (G I). Os valores obtidos variaram de 200 a 330 no grupo experimental, com média de 248 e um erro padrão de 49,7. Houve diferença significante entre os valores das médias nos grupos controle e experimental (552 e 248, respectivamente).

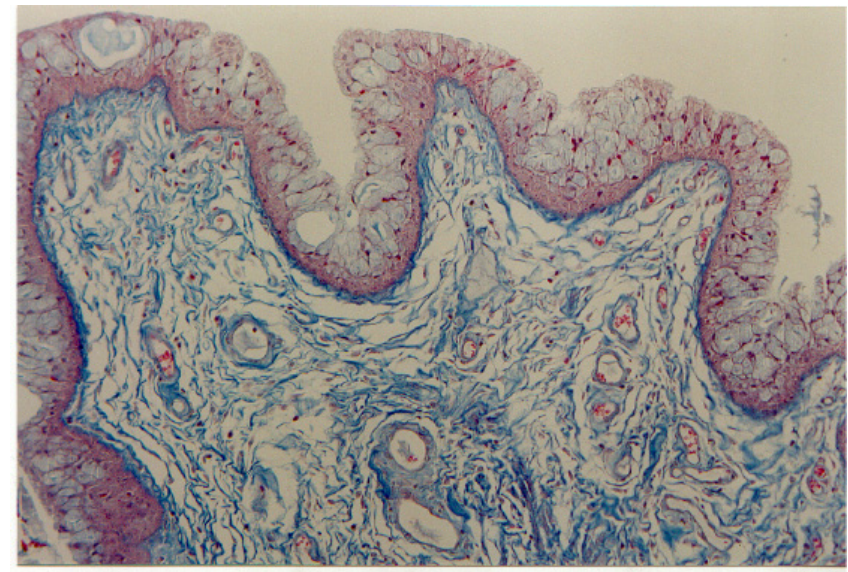

Figura 2B - Fotomicrografia mostrando parte da ectocérvice de rata pertencente ao grupo tratado com hialuronidase. Notar epitélio superficial mucificado delgado (*), lâmina própria rica em vasos sangüíneos e em eosinófilos (setas). Tricrômio de Masson, 200X.

Tabela 1 - Valores da contagem das fibras colágenas na cérvice uterina das ratas no $20^{\circ}$ dia da prenhez no grupo controle (água destilada) e no grupo experimental (hialuronidase).

\begin{tabular}{lcc}
\hline Ratas & Controle & Grupos \\
\hline 1 & 560 & Experimental \\
2 & 600 & 330 \\
3 & 550 & 200 \\
4 & 520 & 220 \\
5 & 530 & 250 \\
Média & 552 & 240 \\
Erro padrão & 31,1 & $248 *$ \\
*Significante & & 49,7
\end{tabular}

\section{Discussão}

Nosso estudo pertence a uma linha de pesquisa que valoriza a indução do trabalho de parto como alternativa para diminuir a incidência de cesárea. As cifras de cesárea de alguns países da América Latina são as mais altas do mundo. O Brasil é um dos países com maiores índices de cesárea de indicação discutível ${ }^{6}$, com cifras de $36 \%$ no setor público e $72 \%$ no setor privado ${ }^{7}$. As taxas alcançam 52\% em São Paulo, 45\% na região Sul e $25 \%$ no Nordeste, sendo maior a proporção em mulheres com mais instrução formal ${ }^{8}$.

Dados anuais do Ministério da Saúde registram que a incidência de gestantes com cesárea anterior tem variado de 20 a 50\% e a repetição da cesárea varia de 50 a 80\%; em certos casos, a antecipação eletiva apresenta complicações clínicas ou obstétricas com risco para o binômio mãe-feto ${ }^{9}$.

As alternativas de contenção dos índices de cesárea se justificam em face da elevação da morbidade e mortalidade associada a este tipo de tocurgia, no mundo todo ${ }^{10}$.

A indução do parto constitui um dos princi- 
pais avanços da obstetricia atual, com o objetivo de evitar riscos materno-fetais e diminuir os indices de cesarianas ${ }^{9}$. Na última década, a incidência mundial de indução variou de 15 a $25 \%{ }^{11}$. Entretanto, para que esta prática funcione efetivamente no combate à cesárea eletiva, devemos buscar condições que a tornem mais acessivel, eficiente e segura. Os variados métodos de indução de parto têm sido escolhidos, principalmente, de acordo com o estado de maturação cervical. Opta-se por aqueles que proporcionam contrações quando a cérvice encontra-se mais madura e reserva-se o uso de agentes facilitadores da maturação cervical quando o colo uterino está pouco preparado.

Como forma mais utilizada, na prática, para avaliar o estado de maturidade cervical, destacamos o índice de Bishop ${ }^{12}$, que consiste em escore com cinco parâmetros (consistência, esvaecimento, dilatação e posição da cérvice uterina, acrescidos da altura da apresentação). Valores inferiores a cinco são indicativos para uso de métodos que atuem primeiramente na maturação cervical, sem determinar o aparecimento precoce de contrações uterinas.

Segundo Garcia ${ }^{13}$, o processo de indução do parto quando a cérvice uterina é imatura, com indice de Bishop baixo, pode ser prolongado, exaustivo e com riscos de falha. Além disso, ocorre maior incidência, no período anteparto, de desconforto materno, taquissistolia, hipertonia uterina, síndrome de hiperestimulação e corioamnionite. Eleva-se, no lado materno, o risco de falha de indução, trabalho de parto prolongado com maiores taxas de corioamnionite e o parto cesáreo ${ }^{14}$.

As prostaglandinas recebem destaque, na literatura médica, como um dos melhores agentes de indução do parto em casos de colo imaturo. $\mathrm{Na}$ cérvice uterina, as prostaglandinas $\mathrm{E}_{2}$ promovem a dissolução de fibras colágenas e aumento do edema submucoso, similares àquelas observadas no início do trabalho de parto ${ }^{15}$. Apesar da boa eficácia com o uso intracervical e de baixas doses, essas preparações são caras e sensiveis ao clima tropical, dificultando sua utilização em países em desenvolvimento ${ }^{16}$.

Destacamos, sobretudo em nosso meio, o misoprostol, análogo sintético da prostaglandina $\mathrm{E}_{1}$, descoberto em 1973. Este atua na maturação cervical pelo aumento da atividade da colagenase e estímulo da atividade uterina em todas as fases da gestação ${ }^{16}$. Entretanto, este fármaco somente pode ser comercializado para uso restrito a estabelecimentos hospitalares devidamente cadastrados e credenciados junto à autoridade sanitária competente. O seu uso é associado a elevadas taxas de taquissistolia, sendo contra-indicado para pacientes com cesárea prévia ${ }^{10-17}$.

Pela dificuldade na escolha do método ideal para indução do parto, a hialuronidase vem sendo utilizada para facilitar a maturação cervical. Não havia, na literatura, resultados histológicos comprobatórios de que a dose preconizada atualmente ocasionasse alterações estruturais significantes. Esta foi a proposta fundamental de nosso estudo.

Há décadas a rata vem sendo estudada por suas características bioquímicas, biomecânicas e avaliação das alterações histológicas na cérvice uterina ao longo da gestação, prestando-se adequadamente para esse tipo de investigação ${ }^{18,19}$. Obviamente, o experimento permitiu a obtenção de material histológico do grupo controle, o que seria de dificil execução em seres humanos, esbarrando em problemas éticos.

Entendemos que o tamanho da nossa amostra (dez ratas distribuídas em dois grupos) foi adequada, e apuramos modificações estruturais semelhantes em todos as ratas de cada grupo (experimental e controle). A dose preconizada por nós teve como parâmetro a medida proporcional ao peso corpóreo em humanos, visando obter correlação clínica mais consistente. Com relação ao dia de aplicação, procuramos realizá-la no final do ciclo gravídico da rata $\left(18^{\circ} \mathrm{dia}\right)$, em dose única, com o objetivo de evitar interferências na fisiologia gestacional. Lembramos que, em humanos, tem sido proposto o uso clínico no termo da gravidez.

Nosso grupo controle foi constituído de infusão intracervical de água destilada, que é o veículo para diluição da hialuronidase no grupo experimental. Superamos a dificuldade da infusão intracervical uterina de água destilada e hialuronidase na rata, utilizando um guia plástico que foi facilmente introduzido na vagina do animal. A própria hipertrofia cervical talvez tenha contribuído e facilitado a ministração da droga.

Os resultados de nosso estudo demonstraram que a ação da hialuronidase promoveu mudanças estruturais importantes na ectocérvice. A sua morfologia no grupo experimental diferenciouse do grupo controle pela presença de epitélio superficial mucificado delgado e lâmina própria caracterizada por tecido conjuntivo frouxo, vasos sanguíneos dilatados e predomínio de eosinófilos. A contagem de fibras colágenas, no grupo experimental, revelou número significantemente menor, quando comparado com o grupo controle. A literatura tem destacado alterações na concentração do colágeno durante a gravidez, realçando que a sua degradação e reorganização provavelmente contribuem para o processo de dilatação ${ }^{20,21}$.

Como vantagens do produto, parece-nos relevante seu manejo ambulatorial, de baixo custo por unidade aplicada, sem riscos biológicos ao binômio mãe-feto, controle simples, além da boa aceitabilidade pela paciente e profissionais de saúde e fácil aplicação. Além disso, não interfere na atividade uterina, atuando somente nas interligações celulares cervicais, ou seja, provoca mudanças cervicais fisiológicas sem provocar con- 
tração ou hiperestimulação uterina. Nas doses empregadas clinicamente a droga não se infiltra na região do segmento inferior, permitindo sua utilização em pacientes com cesariana prévia ${ }^{4}$.

Os resultados do nosso estudo experimental permitem concluir que a injeção intracervical de hialuronidase promoveu alterações histológicas evidentes, características de maturação cervical (lâmina própria da ectocérvice constituída por tecido conjuntivo mais frouxo e concentração menor de fibras colágenas), permitindo ilação clínica que corrobora o uso de hialuronidase em humanos, com esta finalidade.

\section{ABSTRACT}

Purpose: to assess the morphological and morphometric alterations in the uterine cervix of pregnant albino rats determined by local hyaluronidase administration.

Methods: ten rats with a positive pregnancy test were randomly distributed into two equal groups. The control group consisted of rats that received a single dose of $1 \mathrm{~mL}$ distilled water in the uterine cervix, on gestational day 18, under anesthesia. The experimental group consisted of rats that received $0.02 \mathrm{~mL}$ hyaluronidase, diluted in $0.98 \mathrm{ml}$ distilled water (total $=1$ $m L)$, in the same conditions as those of the control group. On day 20, the rats were anesthetized and submitted to dissection. The uterine cervix was prepared for morphological and morphometric study at light microscopy (hematoxylin and eosin, and Masson trichrome).

Results: in the experimental group, greater thinning of the superficial mucified epithelium was observed, with lamina propria rich in blood vessels and eosinophils. Diversely, the control group showed a large concentration of collagen fibers. The histometric analysis in the experimental group was characterized by a smaller number of collagen fibers (mean $=248$ versus 552 of control; $S D=49.7$ versus 31.1 of control). The parametric method (Student's t test) showed a significant difference between groups $(p<0.0001)$.

Conclusion: the local use of hyaluronidase in the cervix of pregnant rats determined predominance of loose connective tissue and a smaller concentration of collagen fibers.

KEYWORDS: Labor. Cervical ripening. Hyaluronidase. Collagen.

\section{Conflito de interesses: não relatado}

\section{Referências}

1. Shi L, Shi SQ, Saade GR, Chwalisz K, Garfield RE. Studies of cervical ripening in pregnant rats: effects of various treatments. Mol Hum Reprod 2000; 6:382-9.

2. Kavanagh J, Kelly AJ, Thomas J. Hyaluronidase for cervical priming and induction of labour. Cochrane Database Syst Rev 2001; (2):CD003097.

3. Belizan JM, Althabe F, Barros FC, Alexander S. Rates and implications of caesarean sections in Latin America: ecological study. BMJ 1999; 319:1397-402.
4. Spallicci MDB. Estudo clínico aleatorizado com grupo controle e mascaramento duplo da maturação do colo uterino pela hialuronidase em gestações a termo [tese]. São Paulo: Univ. de São Paulo; 2002.

5. Surita FGC. Hialuronidase versus sonda Foley para o preparo cervical em gestações com indicação de indução do parto [tese]. Campinas: Univ. Estadual de Campinas; 2002.

6. Souza E, Sass N, Camano L. Análise crítica dos índices de operação cesariana. In: Morais EM, Mauad Filho F, editores. Medicina Materna e Perinatal. $1^{\text {a }}$ ed. Rio de Janeiro: Revinter; 1997. p.200-6.

7. Potter JE, Berquo E, Perpetuo IH, et al. Unwated caesarean sections among public and private patients in Brazil: prospective study. BMJ 2001; 323:1155-8.

8. Hopkins K. Are Brazilian women really choosing to deliver by cesarean? Soc Sci Med 2000; 51:725-40.

9. Ministério da Saúde. Secretaria de Políticas de Saúde. Área Técnica da Saúde da Mulher. Parto, aborto e puerpério: assistência humanizada à mulher. Brasília: Ministério da Saúde; 2001.

10.ACOG - American College of Obstetricians and Gynecologists. Response to Searle's drug warning on misoprostol. Washington, DC: American College of Obstetricians and Gynecologists; 2000. (ACOG committee opinion $\mathrm{n}^{\circ}$ 248).

11.Harman $\mathrm{JH} \mathrm{Jr}$, Kim A. Current trends in cervical ripening and labor induction. Am Fam Physician 1999; 60:477-84.

12.Bishop EH. Pelvic scoring for elective induction. Obstet Gynecol 1964; 24:266-8.

13. Garcia MT. Misoprostol como indutor de trabalho de parto em gestantes com feto vivo a termo [tese]. São Paulo: Univ. Federal de São Paulo; 1999.

14. Morais EN, Mauad Filho F, Gallarreta FMP, Spara P. Indução do trabalho de parto com ocitocina. GO Atual 1998; 10:27-40.

15. Rayburn WF. Induction of labor: indications and techniques. In: Repke JT, editor. Intrapartum Obstetrics. $1^{\text {st }}$ ed. New York: Churchill Livingstone; 1996. p.109-18.

16.Mariani Neto C, Leão EJ, Barreto EMCP, Kenj G, Aquino MMA, Tuffi VHB. Uso do misoprostol para indução do parto com feto morto. Rev Paul Med 1987; 105:325-8.

17.Humphrey RG, Carlan SJ, O’Leary TD. Misoprostol for cervical ripening in patients with previous cesarean delivery. Obstet Gynecol 2000; 95 Suppl:70S.

18.Harkness MLR, Harkness RD. Changes in the physical properties of the uterine cervix of the rat during pregnancy. J Physiol (Lond) 1959; 148:524-47.

19. Golichowski A. Cervical stromal interstitial polysaccharide metabolism in pregnancy. In: Naftolin F, Stubblefield PG, editors. Dilatation of Uterine Cervix. $1^{\text {st }}$ ed. New York: Raven Press; 1980. p.99-112.

20.Kobayashi H, Sun GW, Tanaka Y, Kondo T, Terao T. Serum hyaluronic acid levels during pregnancy and labor. Obstet Gynecol 1999; 93:480-4.

21.Leppert PC, Kokenyesi R, Klemenich CA, Fisher J. Further evidence of a decorin-collagen interaction in the disruption of cervical collagen fibers during rat gestation. Am J Obstet Gynecol 2000; 182:805-11.

Recebido em: 7/4/2003 Aceito com modificações em: 28/4/2003 